\title{
Sorghum genotype may reduce low-grade inflammatory response and oxidative stress and maintains jejunum morphology of rats fed a hyperlipidic diet
}

\author{
Érica Aguiar Moraes ${ }^{a}, *$, Dorina Isabel Gomes Natal a, Valéria Aparecida Vieira Queiroz ${ }^{\text {b }}$ \\ Robert Eugene Schaffert ${ }^{b}$, Paulo Roberto Cecon ${ }^{c}$, Sérgio Oliveira de Paula ${ }^{d}$, Laércio dos Anjos Benjamim ${ }^{e}$, \\ Sônia Machado Rocha Ribeiro a , Hércia Stampini Duarte Martino a \\ ${ }^{a}$ Nutrition and Health Department, Federal University of Viçosa, Av. PH Holfs, s/n, 36570-000, Viçosa, MG, Brazil \\ ${ }^{\mathrm{b}}$ Embrapa Corn and Sorghum, Center for Genetic Resources and Cultivar Development, Rodovia MG 424, km 65, P.O. Box 151, 35701-970, Sete Lagoas, MG, Brazil \\ c Statistics Department, Federal University of Viçosa, Av. PH Holfs, s/n, 36570-000, Viçosa, MG, Brazil \\ ${ }^{d}$ General Biology Department, Federal University of Viçosa, Av. PH Holfs, s/n, 36570-000, Viçosa, MG, Brazil \\ e Veterinary Medicine Department, Federal University of Viçosa, Av. PH Holfs, s/n, 36570-000, Viçosa, MG, Brazil
}

\section{A R T I C L E I N F O}

\section{Article history:}

Received 15 April 2012

Accepted 17 July 2012

Available online 25 July 2012

\section{Keywords:}

Anthocyanins

Phytate

Tannin

Interleukin-6

Interleukin-8

Tumor necrosis factor- $\alpha$

\begin{abstract}
A B S T R A C T
The effects of adding sorghum of various genotypes to a hyperlipidic diet were assessed in adult Wistar rats ( 5 groups $/ \mathrm{n}=10$ ). The diets compared include a negative control diet consisting of the AIN-93M diet (NCD), a hyperlipidic, positive control diet (HCD), and hyperlipidic diets with added sorghum flour of genotypes BRS 305 (HSD 305), BRS 309 (HSD 309), and BRS 310 (HSD 310). Physiological effects of this addition were evaluated by assessment of the lipid profile, blood glucose level, oxidative stress, inflammation and jejunum morphology. Total phenolic, condensed tannin, luteolinidin and apigeninidin concentrations were highest in the flour of genotype BRS 305. After 35 days of treatment, body weight gain and epididymal fat values were similar between groups, as well as blood glucose, fructosamine, total cholesterol and HDL-cholesterol, triglycerides, liver enzymes and superoxide dismutase. The HSD 310 group exhibited lower concentrations of thiobarbituric acid reactive substances and TNF- $\alpha$. The villi height of the rats consuming HCD, HSD 305, HSD 309 and HSD 310 did not differ. It may be concluded that BRS 310 sorghum may have the potential to reduce inflammation and oxidative stress without altering the jejunum morphology.
\end{abstract}

(C) 2012 Published by Elsevier Ltd.

\section{Introduction}

Obesity is a disease characterized by disorders in the metabolism of glucose, triglycerides and plasma lipoproteins. In addition, it is associated with the low-grade pro-inflammatory state and oxidative stress (Karaouzene et al., 2011).

The accumulation of fatty tissue, especially visceral adipose tissue, plays an important role in the production of inflammatory cytokines such as tumor necrosis factor- $\alpha$ (TNF- $\alpha$ ), interleukin-1 (IL-1), and interleukin-6 (IL-6). These cytokines are mediators of the inflammation process that stimulates the synthesis of other cytokines, such as interleukin-8 (IL-8), that are related to several inflammatory diseases (Bruun et al., 2004; Hogan, Canning, Sun, Sun, \& Zhou, 2010).

Excessive fatty tissue increases the production of reactive oxygen species, favoring the instigation of oxidative stress through the increased expression of nicotinamide adenine dinucleotide phosphate

\footnotetext{
* Corresponding author at: Departamento de Nutrição, Universidade Federal de Viçosa, Minas Gerais, 36571-000, Brazil. Tel.: +55 313899 2543; fax: +55 313899 2541.

E-mail address: erica_moraes12@hotmail.com (É.A. Moraes).
}

oxidase (NADPH oxidase) and the reduction of antioxidant enzymes such as superoxide dismutase (SOD), catalase and glutathione peroxidase (GSH) (Furukawa et al., 2004). Thus, Robertsa et al. (2006) demonstrated greater expression of NADPH oxidase and malondialdehyde (TBARS) as well as reduction in expression of the enzymes SOD and GSH in the kidneys and aortas of Fisher rats with obesity induced through the ingestion of a diet with high lipid content and simple carbohydrates.

Oxidative stress and inflammation present in obesity are associated with the development of other co-morbidities such as cardiovascular disease, type 2 diabetes mellitus and cancer (Reuter, Gupta, Chaturvedi, \& Aggarwal, 2010). Whole grains may help reduce the risks of co-morbidities associated with obesity. Dietary fiber reduces the absorption of cholesterol and postprandial blood glucose level as well as decreases intestinal transit time (Farrar, Hartle, Hargrove, \& Greenspan, 2008).

In this context, sorghum has a phytochemical composition that includes phenolic acids, tannins, anthocyanins, and phytate, in addition to dietary fiber, which contribute to the high antioxidant capacity of this cereal. It may, therefore, be useful for reducing the risk of chronic diseases (Awika \& Rooney, 2004). However, the intake of some of these phytochemicals, especially tannins, besides contributing to the 
antioxidant activity, may interfere with the villi and intestinal crypt morphology (Campos, Filho, Torres, Furlan, \& Macari, 2007).

Few studies focus on the functional potential of sorghum to affect a chronic disease (Al-Mamary, Molham, Abdulwali, \& Al-Obeidi, 2001; Carr et al., 2005). However, no study has yet evaluated the effect that adding this cereal to the diet would have on oxidative stress or on the low-grade inflammation associated with obesity. Thus, the objective of this study was to evaluate the effect of adding flour from three different sorghum genotypes as a component of a hyperlipidic diet on parameters of oxidative stress, inflammation and jejunum morphology of Wistar rats.

\section{Material and methods}

\subsection{Sorghum flour preparation}

The grains selected and analyzed included sorghum genotype BRS 309 with white pericarp, but without pigmented testa which contained dhurrin, but no tannins. BRS 305 grains consisted of a light brown pericarp with pigmented testa and tannins, but without dhurrin. Finally, BRS 310 grains exhibit red pericarp without pigmented testa and contained neither dhurrin nor tannins (Moraes et al., 2012). All were provided by Embrapa Maize and Sorghum - Sete Lagoas, MG, Brazil.

The sorghum grains were selected manually and subjected to sieving to remove dirt and impurities. In order to obtain flour, grains were exposed to a temperature of $105{ }^{\circ} \mathrm{C}$ in an oven with air circulation (Nova Ética ${ }^{\circledR}$, model 400/6ND, Vargem Grande Paulista, São Paulo) for $30 \mathrm{~min}$ as proposed by Moraes et al. (2012). Then, the grains were ground with pericarp in a knife mill (CW Brasender ${ }^{\circledR}$, Duisburg, Germany).

\subsection{Chemical analysis and antioxidant activity of sorghum genotypes}

Determination of the total phenolic compound content of the flours was performed using the Folin-Ciocalteu method as described by Singleton, Orthofer, Lamuela-Raventós, and Lester (1999). The condensed tannins were measured using the vanillin/ $\mathrm{HCl}$ reaction method as offered by Burns (1971) with modifications according to Maxson and Rooney (1972) and Price, Van Scoyoc, and Butler (1978). The phytate content was determined by ion exchange chromatography and spectrophotometry according to the method of Latta and Eskin (1980) as modified by Ellis and Morris (1986). Determination of the concentration of total anthocyanins was performed by the $\mathrm{pH}$ differential method of Fuleki and Francis (1968) and Giusti and Wrolstad (2001) with modifications according to Awika, Rooney, and Waniska (2004b). The identification and quantification of anthocyanins, luteolinidin and apigeninidin were performed by high performance liquid chromatography (HPLC) (Shimadzu, SCL 10AT VP) according to the chromatographic conditions described by Awika, Rooney, and Waniska (2004a). The antioxidant activity was determined by reacting the extract with the 1,1-diphenyl-2picrylhydrazyl radical (Bloor \& Lester, 2001). The antioxidant capacity value was obtained by the equation: $\mathrm{AAR}(\%)=\left(\right.$ Absorbance $_{\text {control }}-$ Absorbance $\left._{\text {sample }}\right) \times 100 /$ Absorbance $_{\text {control. }}$. All analyses were performed in three replicates and in triplicate.

\subsection{Animals and experimental diets}

At 53 days of age, 50 male Rattus norvegicus Wistar rats were systematically divided into five groups to minimize difference in mean weight among the groups ( $199 \pm 4.8 \mathrm{~g})$. The animals were placed in individual, stainless steel cages and kept at a temperature of $22 \pm$ $3{ }^{\circ} \mathrm{C}$ with a photoperiod of $12 \mathrm{~h}$. Weight gain and food consumption were monitored weekly.

The consumption of total phenolics, condensed tannins, total anthocyanins, luteolinidin, apigeninidin and phytate was estimated according to the consumption of experimental diets with added sorghum, according to the results obtained from chemical analysis of each genotype (Table 3). Then, the concentration of the compounds ingested was divided by the weight gain and the days of experimentation (35 days) according to Ji and Friedman (2003); the values were expressed in grams per kilogram of weight gain per day.

The animal groups received the following diets: AIN-93M (Reeves, Nielsen, \& Fahey, 1993) as the negative control (NCD), hyperlipidic positive control diet (HCD) based on the composition of the D12079B commercial diet (Research Diets ${ }^{\circledR}$ ) adapted for the AIN-93M diet, hyperlipidic diet with flour of grain sorghum of genotype BRS 305 (HSD 305), hyperlipidic diet with flour of grain sorghum of genotype BRS 309 (HSD 309), and hyperlipidic diet with flour of grain sorghum of genotype BRS 310 (HSD 310). The flours of sorghum grains were added to the diets in sufficient amounts to provide $50 \%$ of the dietary fiber consumed. According to the recommendations for feeding rodent diet AIN-93M, the remaining dietary fiber was provided in the form of cellulose (Table 1 ).

In the 35th day, at 88 days of age, the 50 animals were euthanized by anesthesia with isofluran (Isoforine, Cristália ${ }^{\circledR}$ ) after fasting for $10 \mathrm{~h}$ and blood was collected by cardiac puncture. Blood was stored in a heparinized tube, $16 \times 100 \mathrm{~mm}$ (BD Vacutainer ${ }^{\circledR}$ ), with $10 \mathrm{~mL}$ of sodium heparin, and centrifuged at $2865 \times \mathrm{g}$ for $10 \mathrm{~min}$ (Fanem204, São Paulo, Brazil) to separate plasma. The liver and epididymal fat were weighed and immediately frozen in liquid nitrogen. All materials collected were stored at $-80{ }^{\circ} \mathrm{C}$. After testing for concentrations of the enzyme superoxide dismutase, the livers were lyophilized for analysis of lipid peroxidation.

The upper portion of the jejunum of six animals from each experimental group was fixed in Bouin's fluid for a minimum of $24 \mathrm{~h}$ and preserved in $70 \%$ alcohol.

This study was approved by the Animal Experimentation Ethics Committee of the Federal University of Viçosa, Viçosa, MG, Case No $28 / 2010$.

\subsection{Biochemical analysis, lipid peroxidation and activity of superoxide dismutase}

Plasma concentrations of glucose, fructosamine, total cholesterol, high-density lipoprotein (HDL-cholesterol), triglycerides, alanine aminotransferase and aspartate aminotransferase were determined by colorimetric methods according to manufacturer instructions (Bioclin ${ }^{\circledR}$ ). Lipid peroxidation was estimated in plasma and homogenate of lyophilized liver by means of the thiobarbituric acid reactive

Table 1

Composition of the experimental diets ( $\mathrm{g} / 100 \mathrm{~g})$.

\begin{tabular}{llllll}
\hline \multirow{2}{*}{ Ingredients } & \multicolumn{5}{l}{ Experimental diets } \\
\cline { 2 - 6 } & NCD & HCD & HSD 305 & HSD 309 & HSD 310 \\
\hline Casein & 14 & 14 & 11.79 & 10.74 & 11.01 \\
Maltodextrin & 15.5 & 15.5 & 4.9 & 0.86 & 2.2 \\
Corn starch & 46.6 & 5.32 & 0 & 0 & 0 \\
Sucrose & 10 & 34.1 & 34.1 & 34.1 & 34.1 \\
Corn oil & 4 & 1 & 0.43 & 0.32 & 0.33 \\
Butter & 0 & 20 & 20 & 20 & 20 \\
Sorghum 305 with heat treatment & 0 & 0 & 21.2 & 0 & 0 \\
Sorghum 309 with heat treatment & 0 & 0 & 0 & 26.4 & 0 \\
Sorghum 310 with heat treatment & 0 & 0 & 0 & 0 & 24.8 \\
Cellulose & 5 & 5 & 2.5 & 2.5 & 2.5 \\
Mineral mix & 3.5 & 3.5 & 3.5 & 3.5 & 3.5 \\
Vitamin mix & 1 & 1 & 1 & 1 & 1 \\
Choline bitartrate & 0.25 & 0.25 & 0.25 & 0.25 & 0.25 \\
L-Cystine & 0.18 & 0.18 & 0.18 & 0.18 & 0.18 \\
Cholesterol & 0 & 0.15 & 0.15 & 0.15 & 0.15 \\
kcal/g & 3.8 & 4.6 & 4.5 & 4.5 & 4.5 \\
Dietary fiber & - & - & 11.4 & 9.2 & 9.7
\end{tabular}

A Dietary fiber content of flours of sorghum genotypes BRS 305, BRS 309 and BRS 310 used for the calculation of diets, determined by the enzymatic-gravimetric method (AOAC, 2002). 
Table 2

Chemical composition and antioxidant activity of flours of sorghum genotypes BRS 305, BRS 309 and BRS 310 submitted to heat treatment $\left(150{ }^{\circ} \mathrm{C} / 30 \mathrm{~min}\right)$.

\begin{tabular}{lcrr}
\hline Chemical composition & \multicolumn{1}{c}{ BRS 305 } & \multicolumn{1}{c}{ BRS 309 } & \multicolumn{1}{c}{ BRS 310 } \\
\hline Antioxidant activity (\%) & $91.4 \pm 0.53$ & $91.0 \pm 1.00$ & $89.3 \pm 1.13$ \\
Total phenolics (mg/EAG g) ${ }^{\mathrm{A}}$ & $6.82^{\mathrm{a}} \pm 0.35$ & $0.84^{\mathrm{b}} \pm 0.08$ & $0.95^{\mathrm{b}} \pm 0.11$ \\
Condensed tannins (mg/EC g) & $66.8^{\mathrm{a}} \pm 1.71$ & $2.9^{\mathrm{c}} \pm 0.13$ & $12.5^{\mathrm{b}} \pm 2.04$ \\
Anthocyanins $(\mathrm{mg} / \mathrm{g})$ & $3.65 \pm 0.01$ & $3.14 \pm 0.20$ & $3.75 \pm 0.37$ \\
Luteolinidin (mg/g) & $0.33^{\mathrm{a}} \pm 0.0$ & $0.16^{\mathrm{c}} \pm 0.01$ & $0.23^{\mathrm{b}} \pm 0.01$ \\
Apigeninidin (mg/g) & $1.47^{\mathrm{a}} \pm 0.04$ & $0.56^{\mathrm{c}} \pm 0.03$ & $0.76^{\mathrm{b}} \pm 0.14$ \\
Phytate (mg/g) & $3.78^{\mathrm{b}} \pm 0.87$ & $6.95^{\mathrm{a}} \pm 0.70$ & $5.53^{\mathrm{a}} \pm 0.90$ \\
\hline
\end{tabular}

Means \pm Standard deviation; Values not followed by lowercase letters in the lines do not differ by Tukey test $(\mathrm{p}<0.05)$.

A Equivalent $m g$ of gallic acid per gram of flour.

B Equivalent mg of catechin per gram of flour.

substances (TBARS) as an oxidative stress marker at the serum and hepatic levels (Belobrajdic, Lam, Mano, Wittert, \& Bird, 2011; Oliveira et al., 2006). Determination of superoxide dismutase activity was performed in the liver according to the method of Dieterich, Bieligk, Beulich, Hasenfuss, and Prestle (2000). The liver proteins were determined by the biuret method as recommended by the manufacturer (Bioclin $\left.{ }^{\circledR}\right)$.

2.5. The mRNA expression of IL-8, IL-10 and TNF- $\alpha$ by the method of polymerase chain reaction in real time

From the epididymal adipose tissue of three animals in each experimental group, mRNA was extracted using Trizol reagent (Invitrogen ${ }^{\circledR}$ ) according to the manufacturer's guidelines. The cDNA was made using $2 \mu \mathrm{L}$ of mRNA extracted at a concentration of $200 \mu \mathrm{g} / \mu \mathrm{L}$ to which $1 \mu \mathrm{L}$ of random primers (Promega $\AA$ ) and $1 \mathrm{~mL}$ of the enzyme reverse transcriptase M-MuLV (Fermentas ${ }^{\circledR}$ ) were added. Quantification of target genes was performed by the polymerase chain reaction in real time (RT-PCR) using the ABI Prism 5700 Sequence Detection System of quantification by SYBR-Green fluorescence. The cycle of PCR involved initial denaturation at $95{ }^{\circ} \mathrm{C}$ $(10 \mathrm{~min})$, then 40 cycles with $1 \mathrm{~min}$ denaturation $\left(94^{\circ} \mathrm{C}\right), 1 \mathrm{~min}$ annealing $\left(56{ }^{\circ} \mathrm{C}\right)$ and 2 min elongation $\left(72{ }^{\circ} \mathrm{C}\right)$, followed by determination of the standard curve of dissociation. The sequences of the "primers" (Choma Biotechnologies $®$ ) used were: TNF- $\alpha$ sense: $5^{\prime}$ tct caa aac tcg agt gac aag c $3^{\prime}$; TNF- $\alpha$ anti-sense: $5^{\prime}$ ggt tgt ctt tga gat cca tgc 3'; IL-10 sense: $5^{\prime}$ gag aga agc tga aga ccc tct g 3'; IL-10 anti-sense: $5^{\prime}$ tca ttc atg gcc ttg tag aca c 3'; IL-8 sense: $5^{\prime}$ cac ttc aag aac atc cag agt ttg a $3^{\prime}$ e IL-8 anti-sense: $5^{\prime} \mathrm{cca}$ ttc ttg agt gtg gct atg act $3^{\prime}$. The relative expression of the levels of mRNA was normalized to the endogenous control $\beta$-actin.

\subsection{Jejunum morphometry}

Five blades were taken from the jejunum of six rats from each experimental group. Nine semi-serial transversal sections with $3 \mu \mathrm{m}$ (30 $\mu \mathrm{m}$ as minimal intervals) were obtained using a Reichert Jung 2045 rotary microtome with glass knives. Sections were stained with hematoxylin/eosin. Blade analyses were carried out on an Olympus CX31 microscope and images were captured with a digital camera through SC 020 Olympus GetIt Analysis. Ten different fields per animal were captured and 10 villi of each animal were measured. For measurement, villi were intact, with no changes to the epithelial surface, especially at the apex, and those included presented as straight as possible. Care was taken to ensure that the same villus was not measured more than once in different sections. Images of villus height and crypt depth were captured at $100 \times$ magnification. Thickness of the internal and external muscle layers was captured at $400 \times$ magnification using the Image-Pro® Plus version 4.5 .

\subsection{Statistical analysis}

Data analysis was carried out with the software System for Statistical Analysis (SAEG) version 9.1, licensed by the Federal Universidad of Viçosa, considering a significance level of 5\% $(p<0.05)$. Experimental treatments were arranged in completely randomized design with five groups, ten replicates and initial weight as a covariate to assess the effect of sorghum addition to the hyperlipidic diet model. Analysis was made of food consumption, energy consumption, weight gain, epididymal fat, feed efficiency ratio, consumption of lipids and phytochemicals, biochemical parameters, lipid peroxidation and enzyme activity superoxide dismutase. For measurements of jejunum morphometry, 6 replicates were used. The results were analyzed by ANOVA ( $\alpha=5 \%$ ). For significant "F" the post hoc Tukey test at $5 \%$ probability was used to compare the averages of animals fed with the diets NCD, HCD, HSD 305, HSD 309 and HSD 310.

Three replicates were used to compare the effect of diet on the mRNA expression. The Bonferroni test was used at the $5 \%$ level of probability. All data were presented as means and standard deviation.

\section{Results}

\subsection{Chemical analysis of sorghum genotypes}

There was no difference in antioxidant activity and concentration of anthocyanins among all genotypes of sorghum ( $p \geq 0.05)$. The concentration of total phenolics, condensed tannins, luteolinidin and apigeninidin was higher in genotype BRS 305, however, it showed a lower phytate concentration $(\mathrm{p}<0.05)$ (Table 2$)$.

Table 3

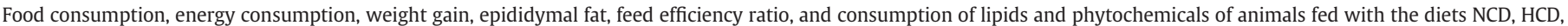
HSD 305, HSD 309 and HSD 310.

\begin{tabular}{|c|c|c|c|c|c|}
\hline Parameters & NCD & $\mathrm{HCD}$ & HSD 305 & HSD 309 & HSD 310 \\
\hline Food consumption (g) & $722^{a} \pm 53.7$ & $616^{\mathrm{b}} \pm 64.2$ & $642^{\mathrm{b}} \pm 78.0$ & $649^{\mathrm{ab}} \pm 70.1$ & $603^{b} \pm 37.8$ \\
\hline Energetic consumption $(\mathrm{kcal} / \mathrm{kg} / \mathrm{d})^{\mathrm{A}}$ & $604 \pm 140$ & $633 \pm 97$ & $661 \pm 162$ & $610 \pm 43$ & $618 \pm 45$ \\
\hline Weight gain $(\mathrm{g})$ & $138 \pm 45$ & $132 \pm 35$ & $136 \pm 50$ & $141 \pm 18$ & $125 \pm 15$ \\
\hline Epididymal fat (g) & $5.85 \pm 1.7$ & $5.12 \pm 1.1$ & $6.32 \pm 2.5$ & $6.03 \pm 3.3$ & $4.73 \pm 1.5$ \\
\hline Feed efficiency ratio & $0.19 \pm 0.06$ & $0.21 \pm 0.05$ & $0.21 \pm 0.05$ & $0.21 \pm 0.01$ & $0.21 \pm 0.02$ \\
\hline Lipids consumption $(\mathrm{g} / \mathrm{kg} / \mathrm{d})^{\mathrm{B}}$ & $8.82^{\mathrm{b}} \pm 2.1$ & $22.5^{\mathrm{a}} \pm 3.5$ & $23.3^{\mathrm{a}} \pm 6.47$ & $24.2^{\mathrm{a}} \pm 1.7$ & $24.5^{\mathrm{a}} \pm 1.8$ \\
\hline Total phenolics $(\mathrm{g} / \mathrm{kg} / \mathrm{d})^{\mathrm{B}}$ & $0^{\mathrm{d}} \pm 0.0$ & $0^{\mathrm{d}} \pm 0.0$ & $0.21^{\mathrm{a}} \pm 0.05$ & $0.029^{\mathrm{c}} \pm 0.0$ & $0.033^{\mathrm{b}} \pm 0.0$ \\
\hline Condensed tannins $(\mathrm{g} / \mathrm{kg} / \mathrm{d})^{\mathrm{B}}$ & $0^{\mathrm{d}} \pm 0.0$ & $0^{\mathrm{d}} \pm 0.0$ & $2.05^{\mathrm{a}} \pm 0.50$ & $0.25^{\mathrm{c}} \pm 0.02$ & $0.43^{\mathrm{b}} \pm 0.03$ \\
\hline Anthocyanins $(\mathrm{g} / \mathrm{kg} / \mathrm{d})^{\mathrm{B}}$ & $0^{\mathrm{b}} \pm 0.0$ & $0^{\mathrm{b}} \pm 0.0$ & $0.11^{\mathrm{a}} \pm 0.03$ & $0.11^{\mathrm{a}} \pm 0.0$ & $0.12^{\mathrm{a}} \pm 0.0$ \\
\hline Luteolinidin $(\mathrm{g} / \mathrm{kg} / \mathrm{d} /)^{\mathrm{B}}$ & $0^{\mathrm{d}} \pm 0.0$ & $0^{\mathrm{d}} \pm 0.0$ & $0.010^{\mathrm{a}} \pm 0.0$ & $0.006^{\mathrm{b}} \pm 0.0$ & $0.007^{\mathrm{b}} \pm 0.0$ \\
\hline Apigeninidin $(\mathrm{g} / \mathrm{kg} / \mathrm{d})^{\mathrm{B}}$ & $0^{c} \pm 0.0$ & $0^{c} \pm 0.0$ & $0.045^{\mathrm{a}} \pm 0.01$ & $0.020^{\mathrm{b}} \pm 0.0$ & $0.025^{\mathrm{b}} \pm 0.0$ \\
\hline Phytate $(\mathrm{g} / \mathrm{kg} / \mathrm{d})^{\mathrm{B}}$ & $0^{\mathrm{d}} \pm 0.0$ & $0^{\mathrm{d}} \pm 0.0$ & $0.12^{\mathrm{c}} \pm 0.03$ & $0.25^{\mathrm{a}} \pm 0.02$ & $0.18^{\mathrm{b}} \pm 0.01$ \\
\hline
\end{tabular}

Means \pm standard deviation; values not followed by lowercase letters in the lines do not differ by Tukey test ( $<<0.05)$. 35 days of food consumption.

A Values expressed in kilocalories of weight gain per day.

B Values expressed in grams per kilogram of weight gain per day. 
Table 4

Biochemical parameters, lipid peroxidation and enzyme activity superoxide dismutase of animals fed with the diets NCD, HCD, HSD 305, HSD 309 and HSD 310.

\begin{tabular}{|c|c|c|c|c|c|}
\hline Parameters & NCD & HCD & HSD 305 & HSD 309 & HSD 310 \\
\hline Glucose (mg/dL) & $112 \pm 23.8$ & $105 \pm 39.8$ & $90 \pm 24.6$ & $99 \pm 23.5$ & $97 \pm 16.7$ \\
\hline Fructosamine $(\mu \mathrm{mol} / \mathrm{L})$ & $128 \pm 11.9$ & $131 \pm 10.3$ & $149 \pm 26.1$ & $135 \pm 12.4$ & $146 \pm 15.4$ \\
\hline Total cholesterol (mg/dL) & $68 \pm 13.0$ & $66 \pm 9.94$ & $67 \pm 13.5$ & $67 \pm 7.6$ & $58 \pm 5.4$ \\
\hline HDL-cholesterol (mg/dL) & $30 \pm 4.6$ & $36 \pm 5.0$ & $33 \pm 6.4$ & $36 \pm 6.5$ & $31 \pm 4.7$ \\
\hline Triglycerides (mg/dL) & $87 \pm 23.8$ & $87 \pm 18.7$ & $68 \pm 19.3$ & $114 \pm 27.5$ & $87 \pm 19.4$ \\
\hline $\operatorname{ALT}(\mathrm{U} / \mathrm{L})^{\mathrm{A}}$ & $53 \pm 12.2$ & $65 \pm 14.8$ & $61 \pm 13.5$ & $67 \pm 9.2$ & $65 \pm 12.7$ \\
\hline $\operatorname{AST}(\mathrm{U} / \mathrm{L})^{\mathrm{B}}$ & $180 \pm 41.0$ & $170 \pm 22.0$ & $176 \pm 40.2$ & $180 \pm 52.7$ & $164 \pm 31.6$ \\
\hline TBARS plasma $(\mathrm{nmol} / \mathrm{mL})^{\mathrm{C}}$ & $8.8 \pm 4.8$ & $7.9 \pm 4.6$ & $6.9 \pm 2.4$ & $6.6 \pm 3.2$ & $5.9 \pm 3.7$ \\
\hline TBARS liver $(\mathrm{nmol} / \mathrm{mg})^{\mathrm{D}}$ & $0.23^{\mathrm{a}} \pm 0.08$ & $0.19^{\mathrm{a}} \pm 0.05$ & $0.22^{\mathrm{a}} \pm 0.01$ & $0.21^{\mathrm{a}} \pm 0.06$ & $0.11^{\mathrm{b}} \pm 0.05$ \\
\hline $\mathrm{SOD}(\mathrm{U} / \mathrm{mg})^{\mathrm{E}}$ & $10.0 \pm 3.4$ & $16.9 \pm 6.7$ & $17.7 \pm 8.2$ & $17.3 \pm 5.9$ & $16.0 \pm 7.7$ \\
\hline
\end{tabular}

Means \pm standard deviation; values not followed by lowercase letters in the lines do not differ by Tukey test $(\mathrm{p}<0.05)$.

A ALT = alanine aminotransferase.

B AST = aspartate aminotransferase.

c TBARS plasma = plasma thiobarbituric acid reactive substances.

D TBARS liver $=$ liver homogenate thiobarbituric acid reactive substances.

E SOD $=$ superoxide dismutase.

\subsection{Food consumption and weight gain}

The food consumption of animals that received NCD diet was greater than that of animals fed with HSD 305 and HSD 310 $(p<0.05)$ and did not differ from the group fed with HSD 309 $(p \geq 0.05)$ (Table 3). However, calorie consumption, body weight, body weight gain, epididymal fat and feed efficiency ratio did not differ between groups ( $\mathrm{p} \geq 0.05)$ (Table 3 ).

The animals that received a diet containing sorghum BRS 305 presented a higher consumption of total phenolics, condensed tannins, luteolinidin, and apigeninidin $(\mathrm{p}<0.05)$ (Table 3$)$. However, the consumption of total anthocyanins was similar between the groups that received diets containing sorghum $(p<0.05)$ (Table 3 ). The phytate consumption was greater for the group fed HSD 309 when compared with those fed with HSD 305 and HSD 310 $(\mathrm{p}<0.05)$ (Table 3$)$.

\subsection{Biochemical analysis, lipid peroxidation and activity of superoxide} dismutase

The plasma concentrations of glucose, fructosamine, total cholesterol, HDL-cholesterol, triglycerides, alanine and aspartate amino transferase, superoxide dismutase and plasma TBARS were similar among groups $(\mathrm{p} \geq 0.05)$ (Table 4$)$.

The concentration of TBARS in the liver was lower in the group fed a hyperlipidic diet added with sorghum BRS 310 than the other experimental groups $(\mathrm{p}<0.05)$ (Table 4$)$.

\section{4. mRNA expression of IL-8, IL-10 and TNF- $\alpha$ by the method of} polymerase chain reaction in real time

There was no difference in the observed mRNA expression of IL-8 and IL-10 between the experimental groups $(\mathrm{p} \geq 0.05)$. However, the expression of TNF- $\alpha$ was lower in the NCD and HSD 310 groups $(\mathrm{p}<0.05)$ (Fig. 2).

\subsection{Jejunum morphometry}

The photomicrography of the villus height and crypt depth, and thickness of the internal and external muscle layers from the jejunum morphology of Wistar rats are presented in Fig. 1A and B, respectively.

There was no difference in the measurement of crypt depth and thickness of internal and external muscles between the groups $(p \geq 0.05)$ (Table 5). The villus height of the groups fed with HSD 305 and HSD 309 was higher than that of animals fed with NCD $(\mathrm{p}<0.05)$, but it did not significantly differ from those fed with HCD and HSD 310 ( $\mathrm{p} \geq 0.05)$ (Table 5).

\section{Discussion}

\subsection{Chemical analysis of sorghum genotypes}

The flours of the three sorghum genotypes exhibited, on average, $90 \%$ antioxidant activity, agreeing with other studies that have demonstrated high antioxidant activity of sorghum, which is higher than that of rice, wheat and oats (Farrar et al., 2008; Ragaee, Abdel-Aal, \& Noaman, 2006).

The genotype BRS 305 presented concentrations of total phenolics and tannins significantly higher than the genotypes BRS 309 and BRS $310(p<0.05)$. The concentration of total phenolics in BRS 305 may be associated with the presence of pigmented testa, a factor that has

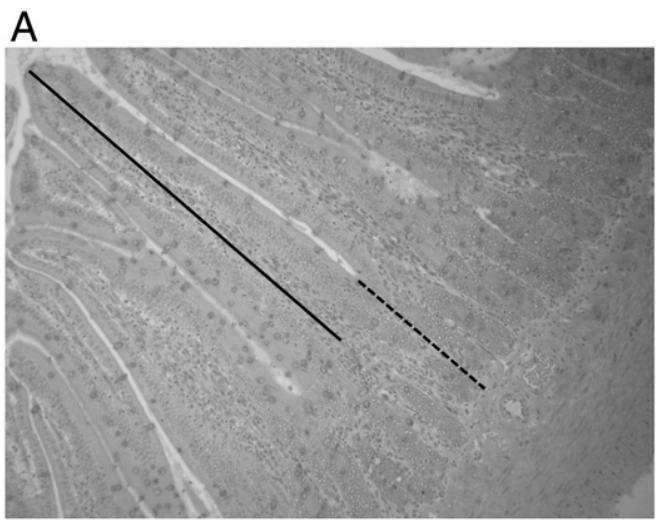

B

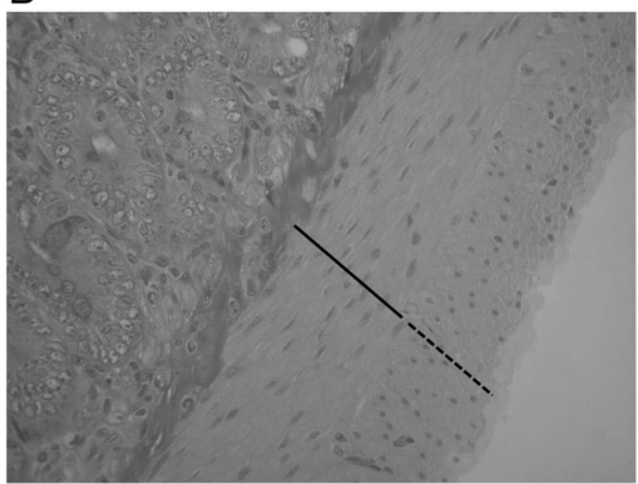

Fig. 1. Photomicrography of the jejunum morphology of Wistar rats stained with hematoxylin/eosin. A) Full line indicates villus height and dashed line crypt depth captured at $100 \times$ magnification. B) Full line indicates thickness of the internal muscle layer and dashed line the external muscle layer captured at $400 \times$ magnifications. 

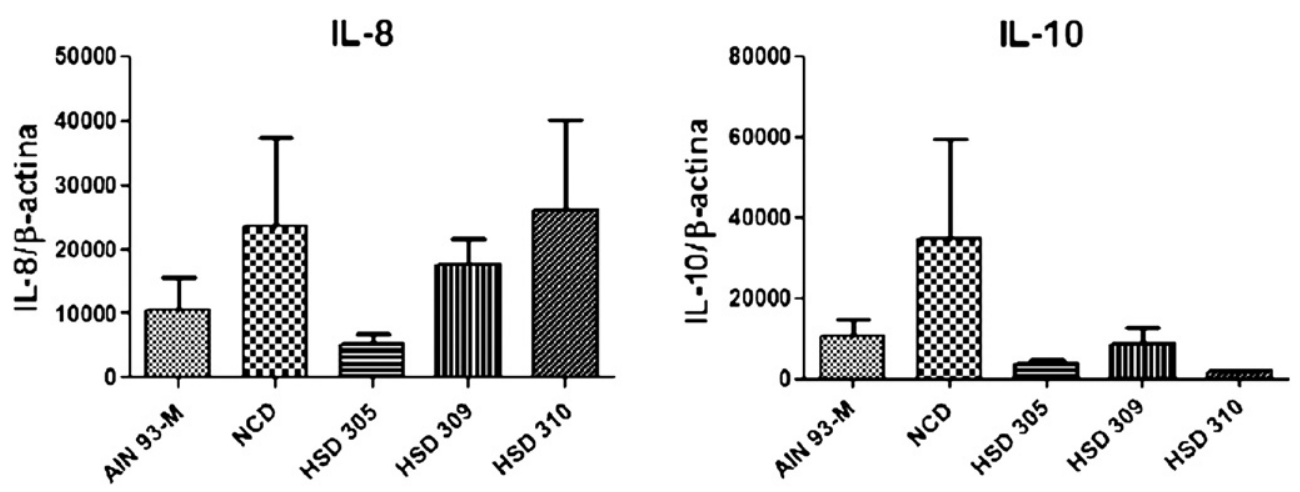

TNF- $\alpha$

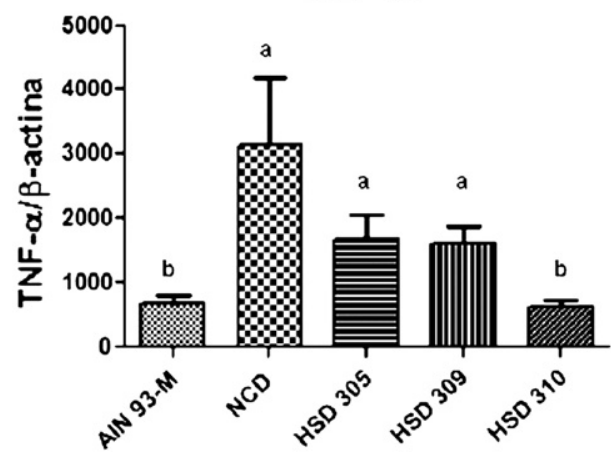

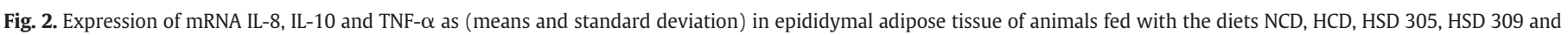
HSD 310.

been correlated to high levels of these compounds. Furthermore, tannins contribute to a larger content of phenolic compounds in sorghum (Awika \& Rooney, 2004). According to Farrar et al. (2008) high levels of phenolic compounds in diets are related to health benefits thus tannins may step up this effect.

The concentrations of luteolinidin and apigeninidin in the genotype BRS 305 (light brown pericarp) represented $50 \%$ of the total anthocyanin content, while for BRS 309 (white pericarp) and BRS 310 (red pericarp) it represented only 23 and 26\%, respectively. Thus, pericarp pigmentation may be related to quantities of these compounds in accordance with results presented by Awika et al. (2004b) in which apigeninidin and luteolinidin accounted for approximately $45 \%$ of the total anthocyanins in genotypes with brown pericarp. Other anthocyanins such as cyanidin and perlagonidin were reported in sorghum; the majority are the 3-deoxyanthocyanins and their derivatives including luteolinidin and apigeninidin, which are unusual in other plants (Awika et al., 2004a, 2004b).

Despite the lower concentrations of total anthocyanins, apigeninidin, luteolinidin, tannins and total phenolics of sorghum BRS 309, it showed an antioxidant activity similar to the other genotypes analyzed. This may be attributable to the higher phytate content of this genotype; due to positioning of the phosphate groups, phytate is able to chelate oxidative ions, thus, it may act as an antioxidant (Kumar, Sinha, Makkar, \& Becker, 2010).

\subsection{Food consumption and weight gain}

The hyperlipidic diets possessed a similar energy density, therefore, they have resulted in similar weight gain and epididymal fat development, although total food consumption was not equivalent to the control. Interestingly, other studies involving hyperlipidic diets found significant differences between the effects of control and hyperlipidic diets (Cole et al., 2011; Wright et al., 2011).

Due to increased consumption of total phenolics, condensed tannins, luteolinidin and apigeninidin in the 305 HSD group, this group was expected to display lower levels of oxidative stress and inflammation. Additionally a study which involved the incorporation of sorghum with higher tannin content into diets prepared for pigs resulted in less weight gain (Al-Mamary et al., 2001). Consequentially, sorghum genotypes with this characteristic could be effective as a strategy to control obesity.

\subsection{Biochemical analyses, lipid peroxidation and activity of superoxide dismutase}

The glucose concentrations, fructosamine, total cholesterol, HDL-cholesterol, triglycerides, alanine and aspartate amino transferase, superoxide dismutase and plasma malondialdehyde did not differ between experimental groups. Contrary to the outcome, it was

Table 5

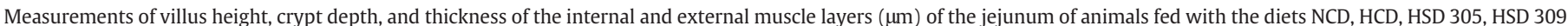
and HSD 310.

\begin{tabular}{|c|c|c|c|c|c|}
\hline Parameters & NCD & HCD & HSD 305 & HSD 309 & HSD 310 \\
\hline Villus height & $368^{\mathrm{b}} \pm 19.1$ & $401^{\mathrm{ab}} \pm 48.4$ & $419^{\mathrm{a}} \pm 33.2$ & $444^{a} \pm 29.9$ & $396^{\mathrm{ab}} \pm 16.8$ \\
\hline Crypt depth & $163 \pm 8.6$ & $169 \pm 14.8$ & $153 \pm 20.5$ & $162 \pm 11.7$ & $152 \pm 18.8$ \\
\hline Internal muscular thickness & $50 \pm 7.4$ & $51 \pm 9.9$ & $57 \pm 10.2$ & $55 \pm 3.4$ & $55 \pm 3.3$ \\
\hline External muscular thickness & $37 \pm 4.8$ & $35 \pm 9.7$ & $36 \pm 8.8$ & $36 \pm 2.5$ & $39 \pm 3.5$ \\
\hline
\end{tabular}

Means \pm standard deviation; values not followed by lowercase letters in the lines do not differ by Tukey test $(p<0.05)$. 
expected that a reduction would be observed in these biochemical parameters in groups that received diets with added sorghum due to the presence of phytochemicals in this cereal.

It has been shown that consumption of diets with higher lipid content induces hepatic lesions through increased oxidative stress and reduces antioxidant enzyme activities (Slim, Toborek, Watkins, Boissonneault, \& Hennig, 1996). In this study, although there was no difference in liver TBARS levels among diets NCD, HCD, HSD 305 and HSD 309, the sorghum genotype BRS 310 reduced this parameter. In this study, the effect of sorghum addition was observed only in liver tissue, probably, due to accumulation of fatty acid peroxides from the experimental diets. According to Mete, Isik, Erdinç, and Gurkan (1999), lipid peroxides accumulate in liver and are not secreted in plasma lipoproteins.

There were no changes in concentrations of liver enzymes (alanine aminotransferase and aspartate aminotransferase) in any of the experimental groups. This result indicates that the three sorghum genotypes showed no risk of toxicity in the parameters analyzed during 35 days of consumption. However, Milagro, Campion, and Martinez (2006) reported changes in Wistar rats fed a hyperlipidic diet for 56 days including increased incidence of liver disorders, aggravation of the metabolic syndrome, and oxidative stress, as indicated by a high concentration of TBARS.

The levels of SOD in the hyperlipidic control group and those which contained added sorghum tended to be $70 \%$ higher than the NCD group. However, Rico, Shin, Um, and Kang (2011) reported lower levels of enzymes SOD, catalase and glutathione peroxidase in mice fed a hyperlipidic diet and highlighted the deleterious effect of lipid consumption on the enzymatic antioxidant system.

\section{4. mRNA expression of IL-8, IL-10 and TNF- $\alpha$ by the method of polymerase chain reaction in real time}

The highest mRNA expression of TNF- $\alpha$, which occurred in the group fed with HCD compared to the negative control (NCD) might confirm the proinflammatory effect of a hyperlipidic diet. It has been shown that increased adiposity is an important mediator of inflammatory processes that contribute to the production of proinflammatory cytokines such as TNF- $\alpha$ (Hotamisligil, Shargill, \& Spiegelman, 1993). However, in this study, the production of these cytokines was observed without statistically significant changes in body weight, epididymal fat and biochemical parameters. Furthermore, a longer period of feeding rats with high fat diets may change these parameters (Belobrajdic et al., 2011; Guo et al., 2012).

The animals fed with HSD 305 and HSD 309 tend to express approximately two times less mRNA of TNF- $\alpha$ than those fed with $\mathrm{HCD}$, although there was no statistical difference. As expression among the HSD 310 group was also lower than among the HCD group $(p<0.05)$, results indicate that sorghum reduced the expression of this cytokine when consumed with a hyperlipidic diet. There is evidence that cereals reduce inflammation (Belobrajdic et al., 2011) considering that pro-inflammatory pathways are regulated by redox signaling (Brasier, 2010). Furthermore, Burdette et al. (2010) explained the inflammation reduction using sorghum bran extracts by decreasing the release of cytokine such as TNF- $\alpha$.

It was found that the HSD 305 group tended toward expression of 3.6 times less mRNA of IL- 8 than the HCD group. This result may be derived from the higher concentration of condensed tannins, called procyanidins in the sorghum genotype BRS 305. An in vitro study with this flavonoid from grape seeds has shown anti-inflammatory and immunomodulatory activities in activated macrophages (Terra et al., 2007).

It is noteworthy that the mechanism that supports the association between obesity and higher levels of inflammation is not fully elucidated. However, the tendency of higher mRNA expression of the TNF- $\alpha$ interleukin and the apparent tendency toward increase in
IL-8 might characterize the presence of subclinical inflammation, especially for animals fed with $\mathrm{HCD}$, without affecting biochemical parameters.

It was observed that IL-10 tended to occur at a rate approximately 2.5 times greater in the HCD group than the NCD group. With sorghum flours added to the hyperlipidic diet, the groups consuming HSD 305, HSD 309 and HSD 310 expressed 7, 3 and 15 times less IL-10 than the HCD group, respectively. Thus, we can infer that this increase comprises a body's response to reduce the production of IL- 8 and TNF- $\alpha$, since IL-10 is the main inhibitor of pro-inflammatory cytokine synthesis and a suppressor of macrophage function.

\subsection{Jejunum morphometry}

Jejunum villus height tended to be higher in animals fed the hyperlipidic diet in the absence and presence of sorghum (HSD 305, HSD 309 and HSD 310); although it has not been statistically different among groups. Moreover, there was no change in crypt depth and thickness of muscle layers. Goda and Takase (1994) reported similar results in rats fed diets with higher lipid content (70\%), highlighting further increase in nutrient absorption surfaces. Scoaris et al. (2010) have related the increase in intestinal absorption surface to greater weight gain in rats fed with the cafeteria diet (16\% lipids). However, in this study, the tendency to increase jejunum villi did not favor weight gain in animals fed a hyperlipidic diet for 35 days.

There were no changes in jejunum morphometric parameters among the animals fed diets containing sorghum. Similarly, broilers fed with sorghum showed no changes in villus height, crypt depth, mucous, or thickness of the intestinal muscle layers indicating a similar morphology to animals fed with wheat and corn (Shakouri, Iji, Mikkelsen, \& Cowieson, 2009).

In this study, the different levels of condensed tannins in sorghum genotypes were not able to alter the jejunum morphology. However, divergent results were shown by Nyamambi, Ndlovu, Naik, and Kock (2007) in which the villus height and intestinal crypt depth were reduced in broilers in accordance with the risein procyanidin concentration of sorghum genotypes. Thus, it can be inferred that the morphological changes were due mainly to the high concentration of lipids in the diet.

Overall, results indicate that the BRS 310 genotype (red pericarp) added to a hyperlipidic diet is more effective than the BRS 305 and BRS 309 genotypes at reducing levels of TNF- $\alpha$ in epididymal adipose tissue and TBARS in liver. The differences observed among the varying sorghum genotypes in this study may be attributed to the polyphenolic content of the grains. Dykes, Seitz, Rooney, and Rooney (2009) demonstrated that sorghum grains with red pericarp had higher levels of flavones. Burdette et al. (2010) reinforced this idea using sumac sorghum (red pericarp) with higher phenolic content and antioxidant capacity than the black one. Then, the anti-inflammatory efficiency of sorghum genotypes depends on individual phenolic constituents.

The selection of foods that have high antioxidant activity and their inclusion in the diet can promote the reduction of risk factors associated with the development of chronic diseases. However, additional in vivo studies are particularly needed to explore the potential beneficial health effects of cereals with high antioxidant potential since they are prevalent in Western diets.

\section{Conclusion}

The flours of sorghum genotypes BRS 305, BRS 309 and BRS 310 showed high antioxidant activity. The sorghum genotype BRS 305 showed the highest concentrations of total phenolics, condensed tannins, luteolinidin and apigeninidin.

Reduced expression of TNF- $\alpha$ in epididymal adipose tissue and lower levels of TBARS in the livers of adult male Wistar rats in the 
group fed a hyperlipidic diet with BRS 310 sorghum may indicate that sorghum has the potential to reduce inflammation and oxidative stress. In addition, the presence of sorghum does not alter the jejunum morphology. Concentrations of plasma biochemical parameters of liver toxicity as well as TBARS and SOD enzyme activity in the liver did not differ between rats fed a hyperlipidic diet or a hyperlipidic diet with added sorghum during a 35 day trial.

\section{Acknowledgment}

Thanks are due to Julia D. Nelson of the Texas A\&M University Department of Nutrition and Food Science for translation of the manuscript, as well as to the Brazilian Agricultural Research Corporation Embrapa Maize and Sorghum for supplying the analyzed sorghum genotypes and the financial support.

Scholarship: Coordenação de Aperfeiçoamento de Pessoal de Nível Superior - CAPES.

Research support: National Counsel of Technological and Scientific Development - CNPq/Brazil.

\section{References}

Al-Mamary, M., Molham, A. -H., Abdulwali, A. -A., \& Al-Obeidi, A. (2001). In vivo effects of dietary sorghum tannins on rabbit digestive enzymes and mineral absorption. Nutrition Research, 21(10), 1393-1401.

AOAC (2002). Association of official analytical chemists. Official methods of analysis of the AOAC International (17th ed.). Gaithersburg, MD, USA: Association of Analytical Communities.

Awika, J. M., \& Rooney, L. W. (2004). Sorghum phytochemicals and their potential impact on human health. Phytochemistry, 65(9), 1199-1221.

Awika, J. M., Rooney, L. W., \& Waniska, R. D. (2004a). Anthocyanins from black sorghum and their antioxidant properties. Food Chemistry, 90(1-2), 293-301.

Awika, J. M., Rooney, L. W., \& Waniska, R. D. (2004b). Properties of 3-deoxyanthocyanins from sorghum. Journal of Agricultural and Food Chemistry, 52(14), 4388-4394.

Belobrajdic, D., Lam, Y., Mano, M., Wittert, G., \& Bird, A. (2011). Cereal based diets modulate some markers of oxidative stress and inflammation in lean and obese Zucker rats. Nutrition and Metabolism, 8(1), 27.

Bloor, S. J., \& Lester, P. (2001). Overview of methods for analysis and identification of flavonoids. Methods in enzymology, Vol. 335. (pp. 3-14): Academic Press.

Brasier, A. R. (2010). The nuclear factor- $\kappa B-i n t e r l e u k i n-6$ signalling pathway mediating vascular inflammation. Cardiovascular Research, 86(2), 211-218.

Bruun, J. M., Lihn, A. S., Madan, A. K., Pedersen, S. B., Schiøtt, K. M., Fain, J. N., et al. (2004). Higher production of IL-8 in visceral vs. subcutaneous adipose tissue. Implication of nonadipose cells in adipose tissue. American Journal of Physiology Endocrinology and Metabolism, 286(1), E8-E13.

Burdette, A., Garner, P. L., Mayer, E. P., Hargrove, J. L., Hartle, D. K., \& Greenspan, P. (2010). Anti-inflammatory activity of select sorghum (sorghum bicolor) brans. Journal of Medicinal Food, 13(4), 879-887.

Burns, R. E. (1971). Method for estimation of tannin in grain sorghum 1. Agronomy Journal, 63(3), 511-512.

Campos, D. M. B., Filho, D. E. F., Torres, K. A. A., Furlan, R. L., \& Macari, M. (2007) Desenvolvimento da mucosa intestinal e a substituição do milho por sorgo na dieta de pintainhos de corte. Ensaios e Ciência, 5(5), 44-48.

Carr, T. P., Weller, C. L., Schlegel, V. L., Cuppett, S. L., Guderian, D. M., \& Johnson, K. R. (2005). Grain sorghum lipid extract reduces cholesterol absorption and plasma non-HDL cholesterol concentration in hamsters. The Journal of Nutrition, 135(9), 2236-2240.

Cole, M., Murray, A., Cochlin, L., Heather, L., McAleese, S., Knight, N., et al. (2011). A high fat diet increases mitochondrial fatty acid oxidation and uncoupling to decrease efficiency in rat heart. Basic Research in Cardiology, 106(3), 447-457.

Dieterich, S., Bieligk, U., Beulich, K., Hasenfuss, G., \& Prestle, J. (2000). Gene expression of antioxidative enzymes in the human heart: Increased expression of catalase in the end-stage failing heart. Circulation, 101(1), 33-39.

Dykes, L., Seitz, L. M., Rooney, W. L., \& Rooney, L. W. (2009). Flavonoid composition of red sorghum genotypes. Food Chemistry, 116(1), 313-317.

Ellis, R., \& Morris, R. (1986). Appropriate resin selection for rapid phytate analysis by ion-exchange chromatography. Cereal Chemistry, 63, 58-59.

Farrar, J. L. Hartle, D. K., Hargrove, J. L, \& Greenspan, P. (2008). A novel nutraceutical property of select sorghum (sorghum bicolor) brans: Inhibition of protein glycation. Phytotherapy Research, 22(8), 1052-1056.

Fuleki, T., \& Francis, F. J. (1968). Quantitative methods for anthocyanins. Journal of Food Science, 33(1), 72-77.

Furukawa, S., Fujita, T., Shimabukuro, M., Iwaki, M., Yamada, Y., Nakajima, Y., et al. (2004). Increased oxidative stress in obesity and its impact on metabolic syndrome. The Journal of Clinical Investigation, 114(12), 1752-1761.
Giusti, M. M., \& Wrolstad, R. E. (2001). Characterization and measurement of anthocyanins by UV-visible spectroscopy. Current protocols in food analytical chemistry. John Wiley \& Sons, Inc

Goda, T., \& Takase, S. (1994). Effect of dietary fat content on microvillus in rat jejunum. Journal of Nutritional Science and Vitaminology, 40(2), 127-136.

Guo, H., Xia, M., Zou, T., Ling, W., Zhong, R., \& Zhang, W. (2012). Cyanidin 3-glucoside attenuates obesity-associated insulin resistance and hepatic steatosis in high-fat diet-fed and $d b / d b$ mice via the transcription factor FoxO1. The Journal of Nutritional Biochemistry, 23(4), 349-360.

Hogan, S., Canning, C., Sun, S., Sun, X., \& Zhou, K. (2010). Effects of grape pomace antioxidant extract on oxidative stress and inflammation in diet induced obese mice. Journal of Agricultural and Food Chemistry, 58(21), 11250-11256.

Hotamisligil, G., Shargill, N., \& Spiegelman, B. (1993). Adipose expression of tumor necrosis factor-alpha: Direct role in obesity-linked insulin resistance. Science, 259(5091), 87-91.

Ji, H., \& Friedman, M. I. (2003). Fasting plasma triglyceride levels and fat oxidation predict dietary obesity in rats. Physiology \& Behavior, 78(4-5), 767-772.

Karaouzene, N., Merzouk, H., Aribi, M., Merzouk, S. A., Yahia Berrouiguet, A., Tessier, C., et al. (2011). Effects of the association of aging and obesity on lipids, lipoproteins and oxidative stress biomarkers: A comparison of older with young men. Nutrition, Metabolism, and Cardiovascular Diseases, 21(10), 792-799.

Kumar, V., Sinha, A. K., Makkar, H. P. S., \& Becker, K. (2010). Dietary roles of phytate and phytase in human nutrition: A review. Food Chemistry, 120(4), 945-959.

Latta, M., \& Eskin, M. (1980). A simple and rapid colorimetric method for phytate determination. Journal of Agricultural and Food Chemistry, 28(6), 1313-1315.

Maxson, E. D., \& Rooney, L. M. (1972). Evaluation of methods for tannin analysis in sorghum grain. Cereal Chemistry, 49, 719-729.

Mete, N., Isik, B., Erdinç, L., \& Gurkan, F. (1999). The effect of fish oil on liver and plasma MDA and antioxidant status of rats. Traditional Journal of Medical Sciences, 29(1), $1-6$.

Milagro, F. I., Campion, J., \& Martinez, J. A. (2006). Weight gain induced by high-fat feeding involves increased liver oxidative stress. Obesity, 14(7), 1118-1123.

Moraes, É. A., Queiroz, V. A. V., Shaffert, R. E., Costa, N. M. B., Nelson, J. D., Ribeiro, S.M.R., et al. (2012). In vivo protein quality of new sorghum genotypes for human consumption. Food Chemistry, 134(3), 1549-1555.

Nyamambi, B., Ndlovu, L. R., Naik, Y. S., \& Kock, N. D. (2007). Intestinal growth and function of broiler chicks fed sorghum based diets differing in condensed tannin levels. South African Journal of Animal Science, 37(3), 202-214.

Oliveira, C. P. M. S., Coelho, A. M. M., Barbeiro, H. V., Lima, V. M. R., Soriano, F., Ribeiro, C., et al. (2006). Liver mitochondrial dysfunction and oxidative stress in the pathogenesis of experimental nonalcoholic fatty liver disease. Brazilian Journal of Medical and Biological Research, 39, 189-194.

Price, M. L., Van Scoyoc, S., \& Butler, L. G. (1978). A critical evaluation of the vanillin reaction as an assay for tannin in sorghum grain. Journal of Agricultural and Food Chemistry, 26(5), 1214-1218.

Ragaee, S., Abdel-Aal, E. -S. M., \& Noaman, M. (2006). Antioxidant activity and nutrient composition of selected cereals for food use. Food Chemistry, 98(1), 32-38.

Reeves, P. G., Nielsen, F. H., \& Fahey, G. C. (1993). AIN-93 purified diets for laboratory rodents: Final report of the American Institute of Nutrition ad hoc writing committee on the reformulation of the AIN-76A rodent diet. The Journal of Nutrition, 123(11), 1939-1951.

Reuter, S., Gupta, S. C., Chaturvedi, M. M., \& Aggarwal, B. B. (2010). Oxidative stress, inflammation, and cancer: How are they linked? Free Radical Biology \& Medicine, 49(11), 1603-1616

Rico, C., Shin, J. -H., Um, I., \& Kang, M. (2011). Cholesterol-lowering action and antioxidative effects of microbial gum in C57BL/6N mice fed a high fat diet. Biotechnology and Bioprocess Engineering, 16(1), 167-172.

Robertsa, C. K., Barnarda, R. J., Sindhub, R. K., Jurczak, M., Ehdaieb, A., \& Vaziric, N. D. (2006). Oxidative stress and dysregulation of NAD(P)H oxidase and antioxidant enzymes in diet-induced metabolic syndrome. Metabolism, Clinical and Experimental, 55, 928-934.

Scoaris, C. R., Rizo, G. V., Roldi, L. P., de Moraes, S. M. F., de Proença, A. R. G., Peralta, R.M., et al. (2010). Effects of cafeteria diet on the jejunum in sedentary and physically trained rats. Nutrition, 26(3), 312-320.

Shakouri, M. D., Iji, P. A., Mikkelsen, L. L., \& Cowieson, A. J. (2009). Intestinal function and gut microflora of broiler chickens as influenced by cereal grains and microbial enzyme supplementation. Journal of Animal Physiology and Animal Nutrition, 93(5), 647-658

Singleton, V. L., Orthofer, R., Lamuela-Raventós, R. M., \& Lester, P. (1999). Analysis of total phenols and other oxidation substrates and antioxidants by means of folinciocalteu reagent. Methods in enzymology, Vol. 299. (pp. 152-178): Academic Press.

Slim, R. M., Toborek, M., Watkins, B. A., Boissonneault, G. A., \& Hennig, B. (1996). Susceptibility to hepatic oxidative stress in rabbits fed different animal and plant fats. Journal of the American College of Nutrition, 15(3), 289-294.

Terra, X., Valls, J., Vitrac, X., Mérrillon, J. -M., Arola, L., Ardèvol, A, et al. (2007) Grape-seed procyanidins act as antiinflammatory agents in endotoxin-stimulated RAW 264.7 macrophages by inhibiting NFkB signaling pathway. Journal of Agricultural and Food Chemistry, 55(11), 4357-4365.

Wright, L., Brandon, A., Hoy, A., Forsberg, G. B., Lelliott, C., Reznick, J., et al. (2011). Amelioration of lipid-induced insulin resistance in rat skeletal muscle by overexpression of Pgc-1 13 involves reductions in long-chain acyl-CoA levels and oxidative stress. Diabetologia, 54(6), 1417-1426. 